\title{
PLATON: Principles and Conceptual Design of Scientific and Interactive HD Television in the PIONIER Network
}

\author{
Miroslaw Czyrnek*, Cezary Mazurek** \\ Poznań Supercomputing and Networking Center \\ Noskowskiego 12/14, 61-704 Poznań, Poland \\ *e-mail:majrek@man.poznan.pl \\ **e-mail:mazurek@man.poznan.pl
}

(Received: 1 September 2010; revised: 29 October 2010; published online: 23 November 2010)

\begin{abstract}
The results of the PLATON project in the area of HD multimedia production and delivery will provide the community with the integrated service that will promote the research outcome, support the educational scenarios and ease the knowledge sharing. It will also open the possibility to promote locally the content produced in other countries and host/deliver it for better end-user experience. In the paper we present the principles and conceptual design of country-wide service for interactive delivery of HD television within the PIONIER network. The concept covers five functional components which we are describing: media production, digital media repositories, live virtual channels creation and management, scalable content delivery, interactive application-on-demand provisioning (AoD).
\end{abstract}

Key words: HD video content production, digital media management, Content Delivery Networking, high quality media delivery

\section{INTRODUCTION}

Nowadays the National Research and Education Networks (NRENs) play an important role in providing high capacity networking infrastructure for the research community in Europe [1]. In the past years, multigigabit networks were deployed on the national level and interconnected through Géant and cross border fibers. These infrastructures enable the research on next generation networks and protocols, support a broad range of multidisciplinary research through dedicated applications, and allow the community to face the challenges of the future research $[13,2]$. On the other hand, the growth of the capacities provided along with future quality of service and on-demand network provisioning systems [3] pave the new way to the development and deployment of the network demanding applications like HD videoconferencing $[4,5]$ and media delivery [6-8], virtual and augmented reality [9] or $4 \mathrm{~K}$ content distribution $[10,11]$, just to mention a few of them. This will result in the near future in transforming the role of the NREN, as we mostly understand today, from communication into the service provisioning party.
The PLATON project [12], started mid-2009 in Poland, is expected to deliver integrated country-wide services for the research community, through deployment of dedicated infrastructure and applications in the PIONIER network. These services include: HD videoconferencing service, eduroam service, campus computation service, archiving service and scientific interactive HDTV service. The services will become available in mid-2012, as a result of joint efforts of the PIONIER consortium members, funded by the European Regional Development Fund through the Innovative Economy Program (Action: Scientific Infrastructure Development).

In this paper we are focusing on the scientific interactive HDTV service in order to present the efforts taken to deploy the HD multimedia production and delivery infrastructure in the PIONIER network [13]. Principles and conceptual design are presented in Section II. In Section III the main functional elements of the system are described. Section IV covers a description of user's roles and relations with relevant functional elements. The conclusions are provided in Section V. 


\section{PRINCIPLES AND CONCEPTUAL DESIGN OF HDTV SYSTEM}

\section{II.1. The rationale}

The rationale to provide the HD media (production and delivery) country-wide platform supporting the whole content lifecycle is to establish the production, management and delivery of media assets environment that will enable the researchers, students, etc., to take advantage of the digital media tools and infrastructures and to promote the research results, educate, disseminate and share the knowledge. The expected users are, but not limited to, universities, research labs, medical clinics and schools. These entities are highly interested and motivated to use the digital media in their daily operations. Just consider, the people watching a medical operation and able to ask the surgeon in real-time, or imagine students being able to view the lecture recordings, university news and events, students' media art or other types of content any time, any place they want in HD. Go further and imagine that people may interact with this content: annotate it, link, extend, subtract and merge to create new forms of media to be published. This ultimate goal may be delivered seamlessly through the HD media platform.

Since the Interactive Scientific HD Television is defined as a service (namely PLATON U5), belonging to the container of common services in the PIONIER network, all functional elements are to be mapped onto different Metropolitan Area Networks (MANs) and HPC Centres (KDMs). Their roles and tasks are crucial for successful service delivery on a country-wide scale. Such a model for service delivery in the PIONIER network was successfully applied for content distribution for the Polish Public Television $[14,15]$.

The architecture of a platform is based on a set of dedicated systems which support specific functional areas.

\section{II.2. Functions of the system}

The design of the platform architecture was driven by the specification of main functional areas and related hardware facilities. These areas include:

- Media production,

- Live virtual channels creation and management,

- Digital media repositories,

- Scalable content delivery,

- Interactive application-on-demand provisioning AoD). The system depends strongly on a hardware infrastructure provided within the project. Therefore, it was required to design carefully all hardware elements of the platform to ensure that the assumed scale and the performance are achieved.

\section{II.3. Hardware components for media production}

To support media production, 6 production studios, 15 recording studios and 1 outside broadcast van (ob-van) are planned to be deployed in MAN and HPC centres (Fig. 1).

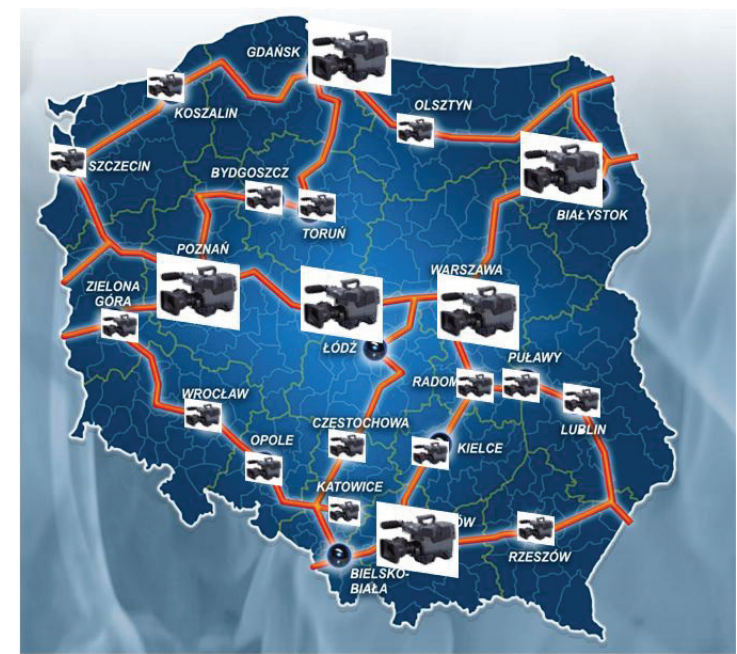

Fig. 1. Media production infrastructure in the PIONIER network

The production studios will be equipped with 3 HD cameras with fiber-optic transceivers, HDSDI router, video mixing, on-air graphics system, recording and play'out devices, steady-cam, video engineering, non-linear video post-production, set of microphones and tripods, audio mixing, audio recording and editing, teleprompter, intercom, lightning etc. The recording studios will be simplified and equipped with 1 HD camera only, a full audio production set and lightning. The ob-van enabling the content production at remote locations will be able to operate up to $6 \mathrm{HD}$ cameras and based on a production studio equipment set. The production infrastructure will enable to create live programmes as well as shot and postproduce different types of on-demand shows, interviews, events, etc. All production facilities will be equipped with media encoders which will encode live feeds with VC1/h.264 codecs and deliver them over IP to live virtual channels systems.

\section{II.4. Digital media repositories}

Two digital media repositories will provide infrastructure, shared for all production facilities, to store, describe with metadata, re-encode and normalize audio tracks (if necessary) of all media assets to be published. We estimate the aggregate storage space to be provided at $120 \mathrm{~TB}$. The stored media assets will be released for distribution and delivery to the end-user through the 
distributed content delivery system (CDS), deployed over the PIONIER network, that will enhance end-user experience and minimize resource usage along with service availability provisioning.

\section{II.5. Scalable content delivery system}

The content delivery system, based on a two-level hierarchical architecture, will consist of 5 regional content centers and 72 proxy/cache servers (in total), deployed in MAN's, responsible for media services delivery to the endusers (Fig. 2). The CDS will be able to serve at least 10000 concurrent users, considering the single HD stream at $10 \mathrm{Mbps}$.

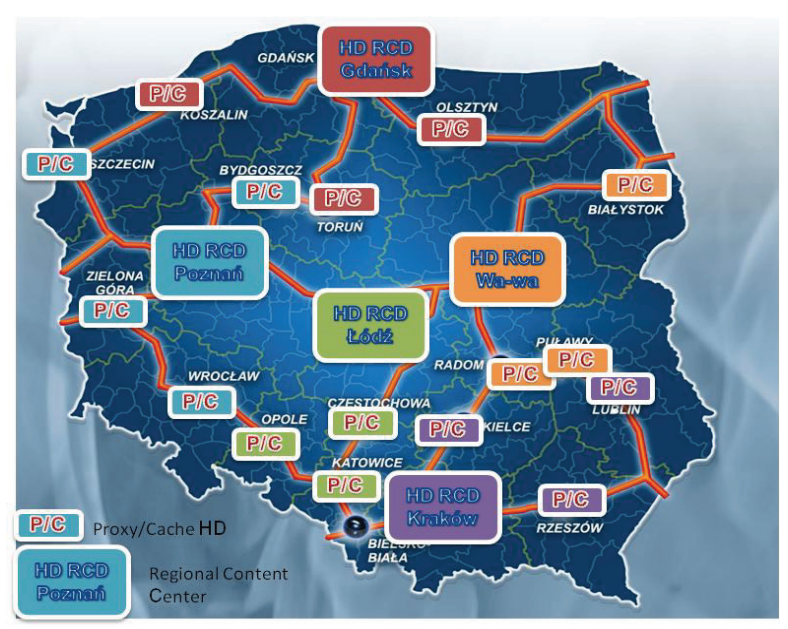

Fig. 2. Content delivery infrastructure in the PIONIER network

The architecture of the CDS will be based on the concept of content distribution deployed in the PIONIER network and used e.g. by the Polish Public Television [16].

\section{FUNCTIONAL ELEMENTS}

\section{III.1. Main functional groups}

The principal functionality of the Interactive Scientific HD Television is to provide services for production, storage, distribution and user access to HD video content. Therefore, all functional elements of the system can be assigned to one of three groups:

- Production group, including HD Content Production, Storage as well as Live Broadcasts

- Delivery group, including HD Content Distribution Network as well as toolbox for Content Management
- Access group, including User Portals, Dedicated AoD service as well as a set of interactive applications.

All functional elements are presented in Fig. 3.

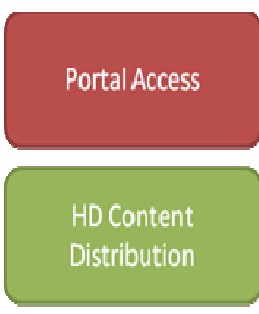

HD Content

Production

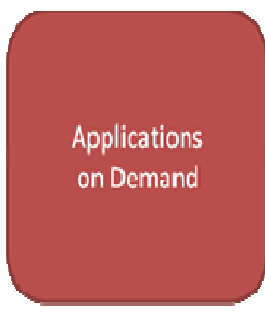

HD Content Storage
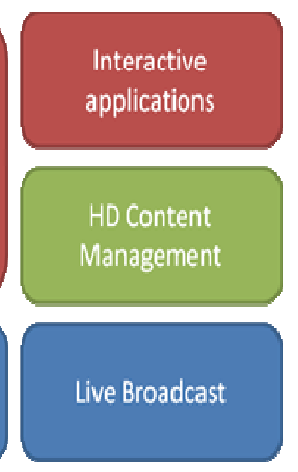

Fig. 3. Functional elements

\section{III.2. Production group}

\section{a) HD Content Production}

HD content production will take place in Production Studios, Recording Studios and Outside Broadcast Van (Mobile Studio). The set of professional tools for producers will be available in every Production Studio. Each studio will be equipped with several independent recording spots, each of them having, as it was described earlier, cameras, audio facilities, lightning etc. Additionally, A/V HD mixers, teleprompters, codecs and archive systems will be used during recordings. Any kind of the HD content will be possible to produce, when using production studio equipment, including video editing, cutting, mixing and sound engineering and video synchronization. Functions for subtitles editing and synchronization or information panels creation will be enabled as well.

The processed $\mathrm{A} / \mathrm{V}$ content will be encoded to different formats and released for repositories for $\mathrm{VoD}$ as well as for Broadcast Servers for "live" delivery.

Production studios will also store the intermediate form of video materials in the external archiving system however, the final form and metadata will be sent to the Content Repository. Materials recorded by Recording Studios will be sent to Production Studios for further processing or (similarly to Production Studio recordings) directly to repositories for $\mathrm{VoD}$ as well as for Broadcast Servers for "live" delivery.

The mobile version of the Production Studio will be constructed in the form of Outside Broadcast Van. It will offer complete Production Studio functionality, with oppor- 
tunity to move to different locations to perform recordings or live broadcast.

\section{b) Content storage}

The Content Repository is the main unit managing the content flow in the system before its delivery. It is responsible for content acquisition from content providers (both interactively from producers and from other system components as a part of defined processing workflows). The Repository functions allow to describe materials, add search criteria, keywords and other metadata useful while searching for materials from the user interface level.

Content stored in the Repository is duplicated for security reasons as well as for better performance and robustness. There are also internal components of the repository system responsible for automatic processing of content, e.g. audio normalization, recoding or digital rights assignment.

The content which is stored in the repository can be ordered for distribution basing on the information about particular material (e.g. the number of $\mathrm{A} / \mathrm{V}$ streams in a file format, video resolution, audio bitrate, etc) and its current locations. The Repository also stores the access frequency for particular material and other statistics.

\section{c) HD Live Broadcasting}

All types of studios are equipped additionally with encoding systems for the purpose of live broadcasting. These systems are providing live video streams for delivery to the Content Distribution System and further on to the enduser. The live broadcast can be the recorded in parallel and then recorded files can be post-processed similarly to other prerecorded content.

\section{III.3. Distribution and management of materials}

Simultaneous access of a large number of users from different locations worldwide to the $\mathrm{VoD}$ and live content can be possible only when the specialized Content Delivery System is applied. In the case of the PLATON HD Television such a system will multiply content and manage all copies located in caching servers, respectively to user requests to serve them in the most efficient way. For the purpose of distribution, materials will be stored in many cache servers, connected to Regional Data Centers which will manage copies of content as well as monitor performance of the whole system.

Since the Content Distribution System is distributed, all enduser requests have to be evaluated to redirect them to a particular proxy/cache server in the optimal way. The evaluation is made with regard to user location, network performance, hardware load of candidate devices.

\section{III.4. User interfaces}

\section{a) Portal access}

The end-user of interactive Scientific HD Television will access available services and content through a set of interactive applications. The main tool which is supposed to be used by users is an interactive portal. It will allow for access to all available materials and searching facilities. The user will also have an opportunity to browse the catalogue of the content being offered. All suitable additional information about the material will be presented in the portal including categories, date and time of production, authors, rights, target user groups, etc. Additionally, the Portal will provide communication services for its users and between users and content produces. The registered user will have an opportunity to comment on the particular video he/she was watching and to provide its evaluation.

\section{b) Applications-on-demand}

The AoD system will provide end-users not only with the content catalogue and search functionality, but also with a set of applications that will enable to interact with the contents published. This will include virtual content manipulation, real time annotation and presentation as well as on-line group-synchronized navigation.

\section{c) Interactive applications}

The realization of the PLATON Television will also result in a set of interactive application for content creation. These application will be available through the web browser and will handle scenarios for remote and interactive creation and processing of a new content. Authorized users will be able to upload their content to the system or to create the new one as a result of post processing of materials available earlier. The developed applications will let them enrich the content with extra information, illustrations, etc., which will be presented to users while broadcasting the main video stream.

One of the most important services provided for authorized users is the creation and management of virtual channels. The live virtual channels systems will enable virtual channel creation and management through setting the play'out order list of the chosen assets, e.g. live feeds and/or archived assets. They will also provide content acquisition functionality and easy-to-use content cutter that will simplify live programmes acquisition and enable quick 
asset export to the digital media repository, for future ondemand use/publication.

\section{III.5. System architecture}

The specification of functional elements of the system leads to the definition of system components and its architecture (Fig. 4).

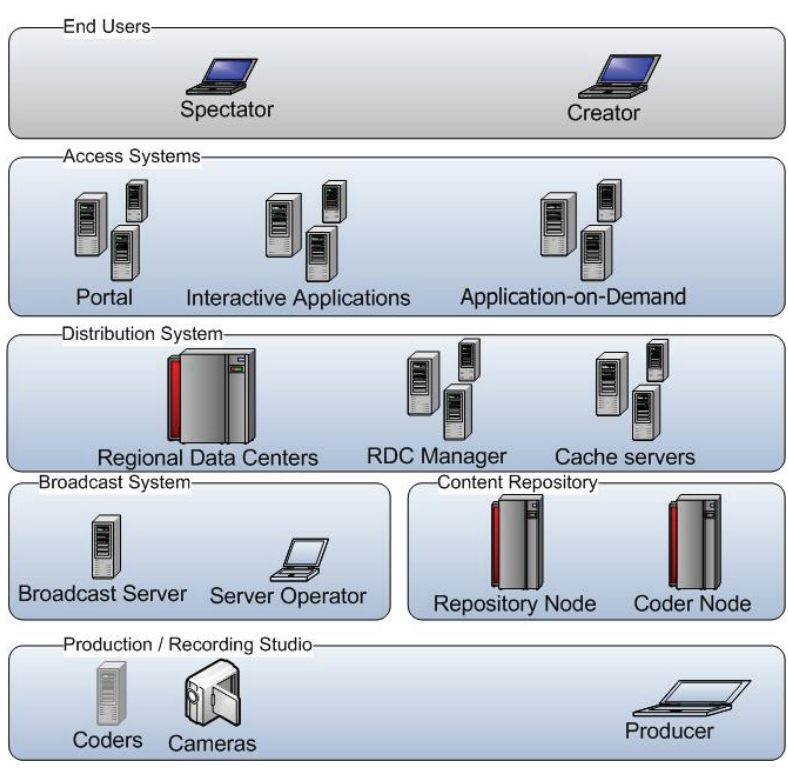

Fig. 4. System components

The service of interactive scientific television in the PIONIER network is composed of the following components:

- Production and recording studios containing facilities like cameras, coders which are to be used by Producers.
- Broadcast Systems which cover software and hardware items which are to be used by Channel Operator.

- Content Repositories, including repository nodes as well as encoding nodes.

- Distribution System built from Regional Data Centers and Cache servers and managed in distributed architecture (RDC Managers).

- Access Systems including Portal, Interactive applications and AoD.

The whole system will be accessed by users who might be either viewers (spectators) or editors (creators).

\section{USER ROLES}

Table 1 presents different roles and components defined within the system and services assigned to them. There are five main roles defined up to now:

- Media Producer,

- Broadcaster,

- Portal editor,

- Content creator,

- Spectator.

The Media Producer is responsible for building a team and gathering means and resources which are necessary for $\mathrm{A} / \mathrm{V}$ content production. The user is the decision maker in the content production process and the outcome of his work is basically HD broadcast either for immediate live delivery or for storing in content repository. The Producer uses all system components assigned to the production group.

The Broadcaster is responsible for configuration of virtual channels which are used for broadcasting of materials coming either from the repository or from coders for live

Table 1. System components and user roles

\begin{tabular}{|c|c|c|c|c|c|}
\hline Role - Component & Producer & Broadcaster & Portal editor & Content Creator & Spectator \\
\hline Production system & Content production & & & & \\
\hline Broadcast system & Live broadcasting & Channel playlist & & & \\
\hline Content repository & Content storage & Sources for playlist & $\begin{array}{c}\text { Metadata for } \\
\text { programme offer }\end{array}$ & & \\
\hline $\begin{array}{l}\text { Content Delivery } \\
\text { System }\end{array}$ & & & & & Content Receiving \\
\hline AoD & & & & $\begin{array}{c}\text { Virtual channels, } \\
\text { interactive } \\
\text { presentation }\end{array}$ & \\
\hline Portal & & & Programme offer & & Content Access \\
\hline
\end{tabular}


transmission. For each of virtual channels the Broadcaster defines the playlist describing the order of materials scheduled for broadcast in the virtual channel. The Broadcast System and Content Repository are components used by the Broadcaster.

The Portal Editor facilitates the access to "live" broadcasts or to materials stored in repository for users. This task is performed through publishing the information about particular material within the Portal and usually building the program offer being presented to users. The Content Repository and Portal management systems are those used by the Portal Editor.

The Content Creator is preparing the presentation of interactive content available on demand. This is done in a few following steps:

- The definition of virtual channels presenting materials selected from the Repository.

- The enrichment of video materials with extra content and information as well as defining the way they are presented.

- The configuration of access rights for particular content.

The performed work results in the definition of presentation of content, which might be in a particular case either single video stream delivery or a well-developed container of materials of different types. The Application on Demand service is the only tool provided for the Content Creator.

The Spectator is the enduser and the recipient of the content who accesses it through the Portal or interactive applications.

\section{CONCLUSIONS}

The Video Content Distribution Network (CDN) developed and successfully deployed within the PIONIER stimulated the advancement of current network services architecture. The fully operational country-wide platform enabling delivery of multimedia over a broadband IP network became the rationale for defining the new common service in the PIONIER network.

Namely, hardware and software infrastructure for HD video production and delivery has been defined as a comprehensive network service, one of five defined in the container of common services within the PLATON project.

PIONIER CDN was earlier used for live transmission of different event (e.g. surgery operations) and made it possible to download recorded video in the VoD mode from a dedicated repository. There were several experi- ments performed with online remote visualization through video CDN for trauma, telepathology and otolaryngology.

Similarly, the proposed HD Interactive Scientific Television is used for video streaming of live events as well as for video on demand delivery. However, there is huge progress in the PLATON HDTV service comparing to the former CDN infrastructure.

The main advantage of a new concept is twofold. First, the service is created together with advanced facilities enabling HD content recording, processing and encoding on a country-wide scale. Second, the set of interactive applications and services for endusers enables new scenarios and use cases to be deployed in the National Research and Educational Network as a foundation of new dimension in broadband networking as well as in media.

The functional concept and architecture of the system which was described in the paper is being developed within the project and will be tested in several phases. The first live transmissions are planned for the beginning of 2011 after all hardware is purchased and the pilot version of the software released.

The main goal of the PLATON Scientific and Interactive HD Television is to provide service to promote the research outcome, to support the educational scenarios and to ease the knowledge sharing. It will also open the possibility to promote locally the content produced in other countries and host/deliver it for better end-user experience. We have made some efforts in this area, just to mention ResearchChannel [16] - which PSNC is a partner, too. We also hope that TERENA's tf-media [18] group will constitute an excellent opportunity to identify, discuss and strengthen the cooperation among different media activities in Europe.

\section{References}

[1] D. Olesen, Collaborative Achievements in European Research and Education Networking. accessed from,http://www.man.poznan.pl/pcss/public/komunikaty/index.html?lang-pl

[2] A. Binczewski, N. Meyer, J. Nabrzyski, S. Starzak, M. Stroiński, J. Węglarz, First experiences with the Polish Optical Internet. Computer Networks 37 (6) 747-760 (2001).

[3] N. Ciulli et al. Architectural approaches for the integration of the service plane and control plane in optical networks. A Computer Networks Journal, Optical Switching and Networking 5 (2, 3), 94-106 (2008).

[4] L. Gharai, T. Lehman, A. Saurin, C. Perkins, Experiences with High Definition Interactive Video Conferencing. IEEE International Conference on Multimedia \& Expo (ICME), Toronto, Canada, July 2006

[5] J. Alcober et al.,High Definition videoconferencing. The future of collaboration in healthcare and education. eChallenges e, 2009 Conference, in press. 
[6] M. Czyrnek, E. Kusmierek, C. Mazurek, M. Stroinski, Large-Scale Multimedia Content Delivery over Optical Networks for Interactive TV Services, Future Generation Computer Systems 22 (8), 1018-1024 (2006).

[7] C. Perkins, L. Gharai, T. Lehman, A. Mankin, Experiments with Delivery of HDTV over IP Networks. Proceedings of the 12th International Packet Video Workshop, Pittsburgh (2002).

[8] E. Kuśmierek, M. Czyrnek, C. Mazurek, M. Stroinski, iTVP: Large-scale content distribution for live and on-demand video services. In: R. Zimmermann, C. Griwodz (eds.) Multimedia Computing and Networking SPIE-IS\&T Electronic Imaging 6504. SPIE (2007). Article CID 6504-8.

[9] L. Matyska, E. Hladka, P. Holub, M. Liska, High Quality Large Scale Virtual Classroom. In: Proceedings of the 14th International Conference of European University Information Systems (EUNIS 2008), Arhus, Denmark (2008).

[10] World's First International Real-time Streaming of $4 K$ Digital Cinema over Gigabit IP Optical Fiber Networks. www.physorg.com/pdf6807.pdf

[11] A. Binczewski, M. Glowiak, B. Idzikowski, M. Stroinski, M. Strozyk New generation media in research and entertainment. presented at TERENA Networking Conference, Vilnius, Lithuania (2010).

[12] PLATON website, http://www.platon.pionier.net.pl/online/?lang=en
[13] J. Nabrzyski, S. Starzak, M. Stroiński, J. Węglarz - „Concept of the Academic and Research European Multicolour Network", ISThmus2000, 11-13. kwietnia 2000, Poznań, pp. 31-38.

[14] M. Czyrnek, C. Mazurek, M. Stroiński, Two-level content delivery system in PIONIER Optical Network for interactive $T V$ services, Ambient multimedia, Bartkowiak M. et al., Proceedings of 11th International Workshop on Systems, Signals and Image Processing, IWSSIP'04, Poznań, PTETiS, 457-460 (2004).

[15] M. Czyrnek, C. Mazurek, M. Stroiński, Management and publishing of digital content on the iTVP Platform, Ambient multimedia, Bartkowiak M. et al., Proceedings of 11th International Workshop on Systems, Signals and Image Processing, IWSSIP'04, Poznań, PTETiS, 481-484 (2004).

[16] M. Czyrnek, E. Kuśmierek, C. Mazurek, M. Stroiński, J. Węglarz, Content Delivery Networks Series: Lecture Notes Electrical Engineering. Buyya, Rajkumar; Pathan, Mukaddim; Vakali, Athena (Eds.) 9 (13), 317-342 (2008).

[17] ResearchChannel, http://www.researchchannel.org

[18] TF-Media: Task Force on Media Management and Distribution. http://www.terena.org/activities/media/
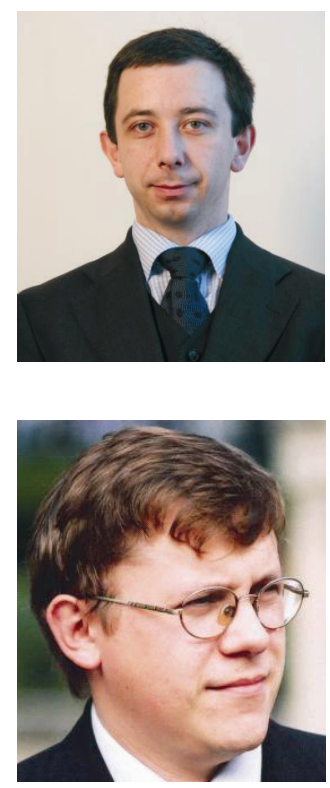

MirosŁaw CzyrneK, M.Sc., received his Master's Degree in Computer Science at the Poznań University of Technology in 2002. Since 1999 he has been actively involved in projects conducted in PSNC Network Services Department, in the area of access portals, advanced network services and multimedia systems. The major ones include: Polish Educational Portal, ATRIUM, iTVP, HDVIPER, NetRadio. Currently he vicemanages the development of scientific interactive HDTV service within PLATON project and horizontally coordinates multimedia activities at PSNC. His interests focus on advanced multimedia technologies deployments in the area of research, education, medicine and entertainment.

Dr Cezary Mazurek is the Head of the Network Services Department at Poznań Supercomputing and Networking Center (www.man.poznan.pl). He received his $\mathrm{PhD}$ in Computer Science from Poznań University of Technology in 2004. His research expertise and experience include a wide variety of advanced network services including digital libraries, interactive television, videoconferencing, telemedicine, data and information management and access to grid services. He has been the manager of numerous projects in those fields coordinated by PSNC, including the Multimedia City Guide, Polish Educational Portal, Digital Library Framework: dLibra, PROGRESS and interactive TV platform. Cezary has been participating in FP6 projects: GridLab, Géant2 and Qualipso. He has also coordinated PSNC's participation in projects Europeana Local, ENRICH, HDVIPER and HIPERMED. Currently he is a leader of activity SA4: Software Governance and project management team member in FP7 Geant3 project. He is the author or co-author of over 50 papers in professional journals and conference proceedings. 